\title{
Solid phase peptide synthesis on chitosan thin films
}

Tadeja Katan ${ }^{\dagger}$, Rupert Kargl ${ }^{\dagger}$, Tamilselvan Mohan ${ }^{\dagger}$, Tobias Alexander Steindorfer ${ }^{\dagger}$, Miran Mozetič $\check{c}^{\ddagger}$ Janez Kovač ${ }^{\ddagger}$, Karin Stana Kleinschek ${ }^{\dagger}$

${ }^{\dagger}$ Graz University of Technology, Institute of Chemistry and Technology of Biobased Systems (IBioSys), Stremayrgasse 9, 8010 Graz, Austria

${ }^{\ddagger}$ Department of Surface Engineering, Jožef Stefan Institute (IJS), Jamova 39, 1000 Ljubljana,

\section{Slovenia}

Table S1. Surface elemental composition of chitosan and neutralized chitosan thin film. Values are in at.\%.

\begin{tabular}{|l|l|l|l|l|l|l|}
\hline Sample & $\mathrm{C}$ & $\mathrm{N}$ & $\mathrm{O}$ & $\mathrm{Na}$ & $\mathrm{Cl}$ & O/C ratio \\
\hline Chitin theor. & 57.1 & 7.1 & 35.7 & 0 & 0 & 0.63 \\
\hline CH_native & $55.4 \pm 0.4$ & $7.3 \pm 0.4$ & $32.2 \pm 0.4$ & 1.1 & $4.0 \pm 1.0$ & 0.58 \\
\hline CH_neutral & $58.9 \pm 0.4$ & $7.3 \pm 0.4$ & $33.6 \pm 0.4$ & 0.1 & 0 & 0.57 \\
\hline CH_neutral theor. & 54.5 & 9.1 & 36.4 & 0 & 0 & 0.67 \\
\hline CH_acetyl & $61.0 \pm 0.8$ & $6.3 \pm 0.4$ & $32.7 \pm 0.8$ & 0 & 0 & 0.54 \\
\hline CH_acetyl theor. & 57.1 & 7.1 & 35.7 & 0 & 0 & 0.63 \\
\hline
\end{tabular}

Table S1. Surface elemental composition of neutralized chitosan and functionalized chitosan thin film. Values are in at.\%.

\begin{tabular}{|l|l|l|l|l|l|}
\hline Sample & C & N & O & Other & O/C ratio \\
\hline
\end{tabular}




\begin{tabular}{|l|l|l|l|l|l|}
\hline CH_neutral & $58.9 \pm 0.4$ & $7.3 \pm 0.4$ & $33.6 \pm 0.4$ & 0.10 .05 & 0.57 \\
\hline CH_neutral theor. & 54.5 & 9.1 & 36.4 & 0 & 0.67 \\
\hline CH_Boc-Gly & $61.3 \pm 0.4$ & $6.9 \pm 0.4$ & $30.7 \pm 0.4$ & $1.1 \pm 0.3$ & 0.50 \\
\hline CH_Boc-Gly theor. & 59.1 & 9.1 & 31.8 & 0 & 0.54 \\
\hline CH_Fmoc-Gly & $61.6 \pm 0.4$ & $7.6 \pm 0.4$ & $30.9 \pm 0.4$ & 0 & 0.50 \\
\hline CH_Fmoc-Gly theor. & 71.9 & 6.2 & 21.9 & 0 & 0.30 \\
\hline CH_Fmoc-Gly-Gly & $62.8 \pm 0.4$ & $7.2 \pm 0.2$ & $30.0 \pm 0.4$ & 0 & 0.48 \\
\hline CH_Fmoc-Gly-Gly theor. & 69.5 & 8.3 & 22.2 & 0 & 0.32 \\
\hline
\end{tabular}

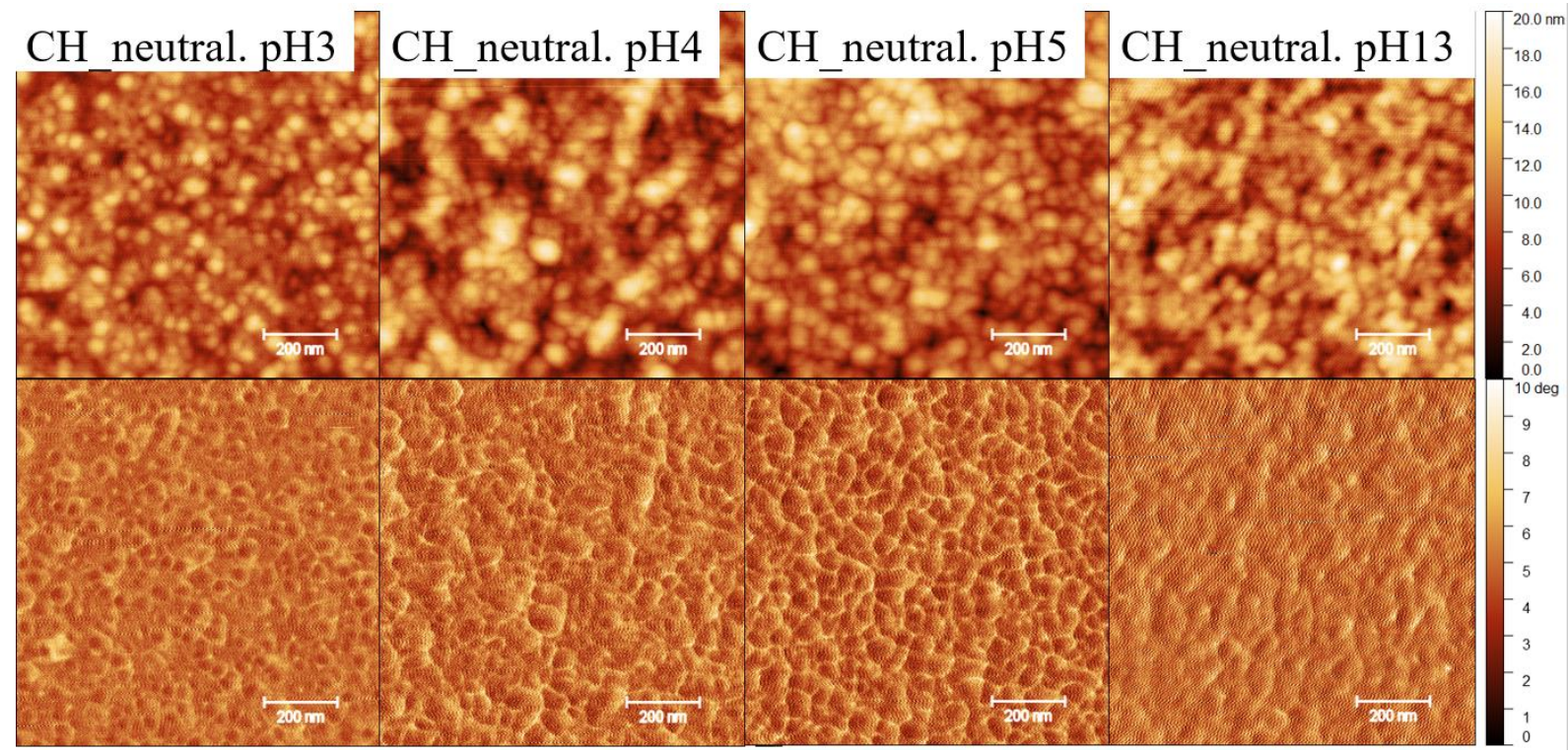

Figure S1. AFM images $(1 \times 1 \mu \mathrm{m})^{2}$. TOP row topography, BOTTOM row phase images:

neutralized chitosan films on QCM-D gold crystals at different $\mathrm{pH}$ exposures. 


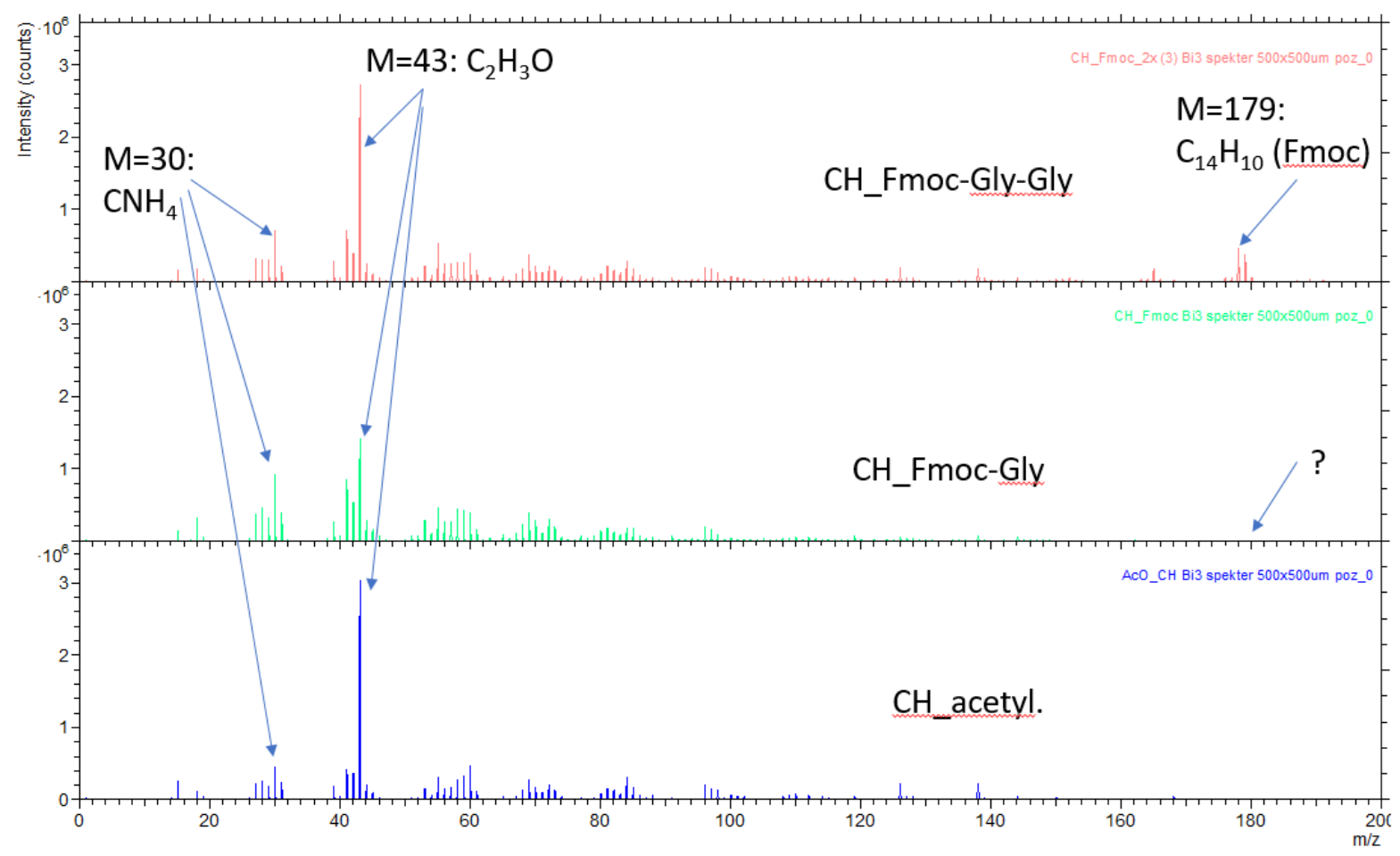

Figure S2. ToF-SIMS spectra of positive secondary ions from functionalized chitosan thin films (CH_Fmoc-Gly-Gly, CH_Fmoc-Gly, CH_acetyl) 


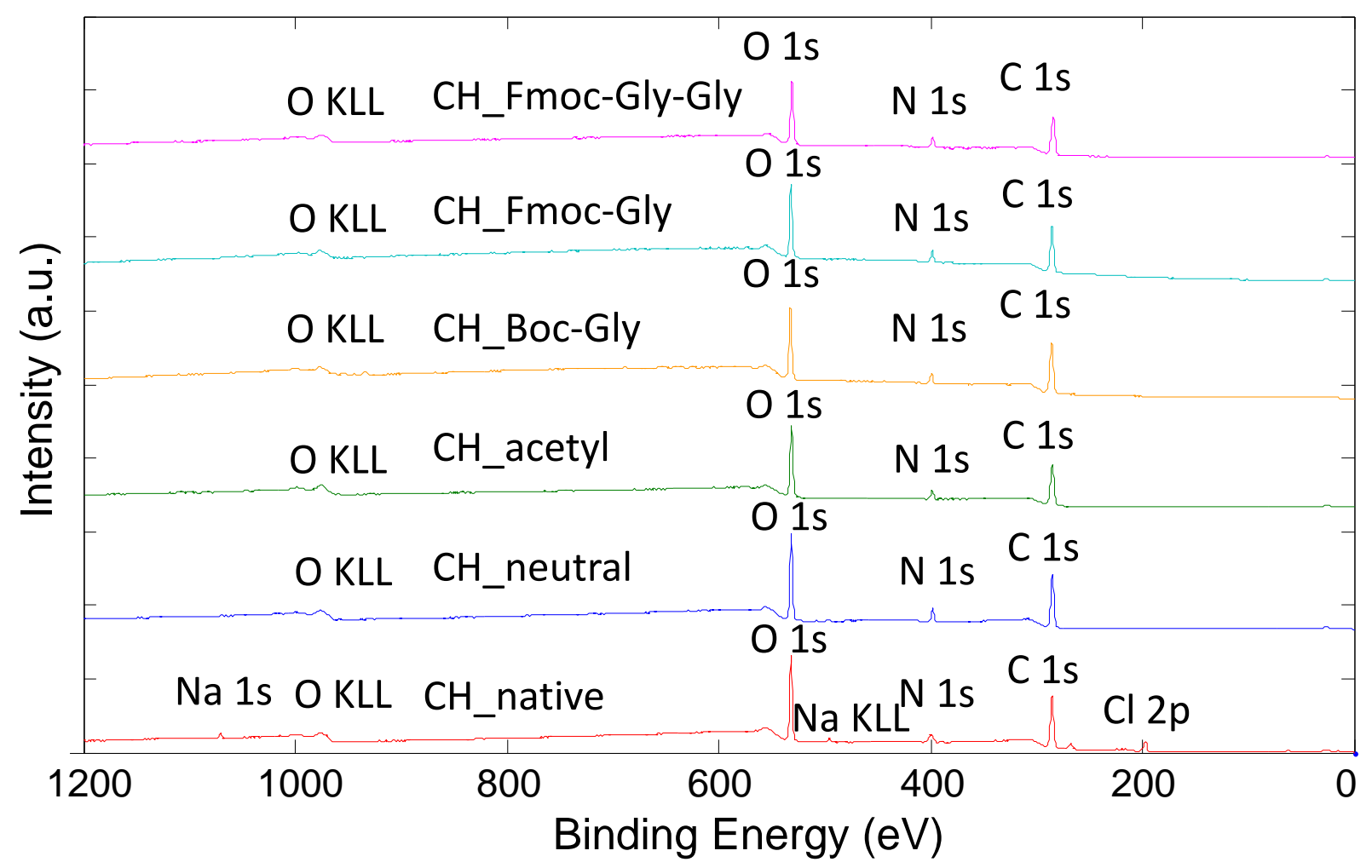

Figure S3. XPS survey spectra of chitosan, neutralized chitosan and functionalized chitosan thin films 